\title{
Potential Risks of Agricultural Intensification in Tropical Catchments: the Case of Lake Naivasha
}

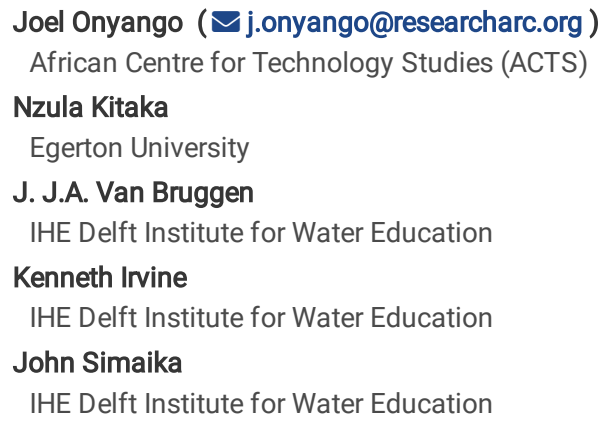

\section{Research Article}

Keywords: nutrients, pesticide residue, DDT, water quality risk, Lake Naivasha, sub-Saharan Africa

Posted Date: February 28th, 2022

DOI: https://doi.org/10.21203/rs.3.rs-1352018/v1

License: @ (i) This work is licensed under a Creative Commons Attribution 4.0 International License. Read Full License 


\section{Abstract}

The use of both fertilizers and pesticides in the Lake Naivasha Catchment, is associated with agricultural intensification and has resulted in enrichment of aquatic ecosystems with nutrients, coupled with exposure of aquatic biota to pesticide residues affecting aquatic ecosystem structure and function. This study explored the changes in land use and related it with the concentrations of nutrients and selected pesticides, to show the potential of combined (nutrients and pesticides) risks associated with agricultural intensification in Lake Naivasha catchment, a tropical catchment in Kenya. The results indicate that between 1989 and 2019 there was an increase of cropland by $623 \mathrm{~km}^{2}$, a reduction of forest cover by $200 \mathrm{~km}^{2}$, increase of grasslands by $534 \mathrm{~km}{ }^{2}$, a reduction in bare soils by $100 \mathrm{~km}^{2}$, and an increase of $540 \mathrm{~km}^{2}$ of built area. The land cover changes were correlated with increased concentrations of nutrients and pesticides in surface waters across sampling sites monitored in 2015. The results further indicated that while the concentrations of nitrogen and phosphorus indicated a potential stoichiometric nitrogen limitation, increase in forest cover resulted in decreased nutrient concentrations in the river water. Concentrations of DDT and technical $\mathrm{HCH}$ active ingredients indicated significant relationships between land use changes and intensification. Areas with extensive farming systems were associated with higher concentrations of TP and $\sum$ DDT compared with areas of high intensification, which may reflect high connectivity between intensive agricultural systems and river ecosystems. When combined nutrients and pesticides were considered, most of the lower reaches of the rivers draining to $\mathrm{L}$. Naivasha were of poor water quality status as defined by Kenyan water quality regulations. The changes in land cover and agricultural intensification in the Naivasha catchment needs management and policy frameworks that manage the combined contamination from nutrients and pesticide residues. Enhanced investment in institutional and policy reforms, and an integrated review of water quality standards and monitoring indicators that combine biological, physical, and chemical monitoring, is necessary for future management of the catchment.

\section{Introduction}

Agricultural intensification focuses on increasing and optimising food production [1]. Sustainable agricultural intensification has been characterised as a strategy that simultaneously feeds humanity while using ecosystems sustainably [2]. In these systems, intensification is associated with efficient production while maintaining an appropriate balance with non-agricultural land [3]. Increased agricultural efficiency requires application of nutrients and pesticides to crops [1], [4]. For example, it has been estimated that intensification of $8-12 \%$ of croplands, will result in an $8-25 \%$ global increase in inorganic phosphorus fertilizer consumption [4].

Rapid population growth in sub-Saharan Africa (SSA) has prompted increased investment in agricultural intensification to meet local food and economic need (Nijbroek and Andelman, 2016). The efforts for intensified agricultural systems in SSA are hindered by low soil nutrient content and its rapid depletion [6], [7], as well as the prevalence of pests and diseases that reduce yields [8]. This has led to the increased application of fertilizers and pesticides (Holden, 2018; Sheahan and Barrett, 2017; Sileshi et al., 2019), and therefore the associated risks of run-off into aquatic ecosystems [12]. The excessive application of nitrogen and phosphorus-based fertilizers have negative impacts on aquatic life and disrupt ecosystem function [13], [14]. Pesticide residues affect the physiology and ecology of aquatic biota including poisoning the organisms, resulting in a loss of local biodiversity [15], [16]. Pesticides and nutrients potentially modify both the presence and distribution of aquatic life and ecological processes. Guiding agricultural sustainability, policy and monitoring on the use of pesticides and fertilizers needs an understanding of the risks associated with combined nutrients enrichment and pesticides exposure. This paper seeks to answer two main questions: (i) How are nutrients enrichment and pesticide contamination linked to land use in a catchment subject to agricultural intensification in sub-Saharan Africa?; and, (ii) what are the risks to ecosystems posed by the contamination in an agricultural catchment?

This study focussed on the Lake Naivasha catchment in Kenya, to illustrate the relevance of assessing combined nutrients and pesticides risk to surface water quality and management in the region. Lake Naivasha catchment is well known for floriculture [17]. Despite efforts to ensure the catchment remains the centre for sustainable utilization of water resources, both surface and ground water in the L. Naivasha basin have been subject to heavy exploitation [18], [19]. However, no studies have explored the combined distribution and risks associated with nutrients and pesticides in the surface waters of the catchment, and how it relates to land use changes. This paper assesses the spatial distribution and associated risks of combined nutrients and pesticides in the L. Naivasha catchment through determining land use and land cover changes.

\section{Materials And Methods}

\subsection{Lake Naivasha Catchment}

Lake Naivasha catchment has an area of $3400 \mathrm{~km}^{2}$, traversing the Nakuru and Nyandarua counties in the central Rift Valley region in Kenya [20]. Lake Naivasha is a designated Ramsar site and the second largest freshwater lake in Kenya. It has an approximate area of $100 \mathrm{~km}^{2}$, and is fed by three main rivers, the Malewa, Gilgil and Karati [21], [22]. The climate is semi-arid, characterized by mean monthly temperatures of 15.9 to $17.8{ }^{\circ} \mathrm{C}$ [23] and a bimodal rainfall pattern with long rains typically from April to May/June and short rains from October to November [17]. Increased agricultural production in the catchment is associated with intensification and land use changes in the area [1]. In these systems, agricultural intensification is associated with land use changes in the area [20]. It is, however, unclear how the intensity of different agricultural activities ranging from horticultural production in the $50 \mathrm{~km}^{2}$ area around the lake [22], to small holder farming in the upper catchment for maize, beans and vegetables [24] contribute to surface water quality over the entire catchment.

\subsection{Sites selection}

Thirteen sampling stations were selected along the rivers Malewa, Gilgil and Karati, and in L. Naivasha (Fig. 1). Wanjohi (M1) and upper Malewa (M2) sites are in the upper reaches of the Malewa River catchment, while Malewa Bush Ventures (M4) occur in the mid reaches, and Malewa Highway (M5) is in the lower. The Turasha site (M3) is a tributary to the Malewa River running from the north-east before entering the Turasha dam. Kahuho site (G1) is in the upper part of the Gilgil River catchment, while Little Gilgil site (G2) is a tributary to the main channel. The Gilgil Highway site (G3) is situated in the lower part of the 
catchment below the Gilgil dam. The only site along the Karati river- the Karati Highway Bridge site (K1), is in the lower reaches of the river. The L. Naivasha sites comprise the River Mouth site (N1) where the Gilgil and the Malewa rivers enter the lake, the Mid-lake site (N2) intended to capture the conditions of the lake as a whole, the Hippo point site (N3), where there was minimal visible impact along the south-western lake shore area, and the Crescent site (N4) on the north-east of the lake, close to the farms on the shores of the lake (Fig. 1).

\subsection{Sampling}

Sampling was done monthly between April and August 2015. In the field, triplicate integrated water samples from each site were collected. At the lake sites (N1, N2, N3 and N4), water samples were taken at different depths (upper 5-30 cm, mid 3-4 m, and bottom 5-7 m depths) and integrated into one consolidated sample. For the river sites, (G1, G2, G3, M1, M2, M3, M4, M5 and K1), the three integrated samples were taken at $5 \mathrm{~cm}$ below the water surface at different points (comprising riffle, run, pool) within a $100 \mathrm{~m}$ sampling site reach. Acid-washed $500 \mathrm{ml}$ polythene bottles were used to collect water samples for nutrient analysis. Water samples for the pesticide analysis were collected in $2.5 \mathrm{~L}$ dry amber glass bottles, pre-washed with distilled water followed by ethanol rinsing. The water samples were transported in a cool box equipped with icepacks to the Egerton University Aquatic Sciences laboratory for nutrients analysis; and to the University of Nairobi Pesticide Research Laboratory for pesticides residues analysis. Sampling was organized to ensure time-replicates with five sampling trips, as well as geographical triplicate samples for the thirteen sites.

\subsection{Laboratory analysis}

In the laboratory, $300 \mathrm{ml}$ of the unfiltered nutrient samples were used to determine total nitrogen (TN) and total phosphorus (TP). TN was determined using the micro Kjeldahl method and TP determined through persulphate digestion followed by ascorbic acid method [25]. The nutrient analysis was done at the Egerton University Aquatic Sciences laboratory. The pesticide residues in the water samples were extracted using Liquid-Liquid extraction method following the UNEP-POP protocol [26], and quantified at the University of Nairobi Pesticide Research Laboratory. To control the quality of the analysis, recovery rates for each pesticide residue were determined from spiked samples, and triplicate samples per site were extracted and analysed. Spiking was done by adding the respective standard of the pesticide residue under investigation. The spiked samples were treated using the same procedure as the field samples. Additionally, distilled water was used as blanks and incorporated with external standards to determine the detection limit of the pesticides investigated. The study focused on residue concentrations of $\mathrm{HCH}$ group ( $\mathrm{a}-\mathrm{HCH}, \beta-\mathrm{HCH}, \mathrm{\gamma}-\mathrm{HCH}, \delta-\mathrm{HCH}$ ), cyclodiene group (Heptachlor, Heptachlor Epoxide, a-endosulfan, $\beta$-endosulfan, endosulfan sulphate, endrin, endrin aldehyde, aldrin, dieldrin, and methoxychlor), and DDT group (pp-DDE, pp-DDD, pp-DDT). The percent recoveries ranged from $70 \%$ to $5 \%$ whie limit of detection ranged from 0.0011 to $0.0036 \mu \mathrm{g} / \mathrm{L}$ (more details in Supplementary Table 1).

\subsection{Concentration and distribution of nutrients and pesticides}

The distribution of the nutrient and pesticide concentration data was tested using a Shapiro-Wilk test and checked visually using Q-Q plots. As the data were not normally distributed they were log-transformed. A Multivariate Analysis of Variance (MANOVA) was used to test differences in concentrations among sampling sites. Linear regression was used to test for the relationship between nutrient and pesticide concentrations across sampling sites. Concentrations among sites were compared using the Kruskal Wallis Test.

\subsection{Inference of nutrients and pesticides concentrations}

The consequences of nutrient and pesticide concentrations to the aquatic ecosystem were assessed using ecologically significant concentration ratios comprising TN:TP; DDD/DDE, (DDE + DDD):DDT and DDT:DDE; and a: $\mathrm{Y}-\mathrm{HCH}$. The stoichiometric TN/TP ratio is an indicator of potential $\mathrm{N}$ or P limitation for phytoplankton primary production, with a molar ratio above 16 indicating potential $P$ limitation [27]. The ratio of DDD/DDE is an indicator of the conditions for DDT biodegradation with a ratio $>1$ indicating anaerobic DDT biodegradation, whereas a ratio < 1 indicates an aerobic DDT degradation [28]. The (DDE + DDD)/DDT ratio is an index for source of DDT, with a ratio $>0.5$ associated with long term weathering of DDT from soils [29]. High ratios of DDT:DDE indicate more recent exposure than lower ratios [30], [31]. The a: $\mathrm{Y}-\mathrm{HCH}$ ratio is an indicator of whether technical $\mathrm{HCH}$ (low insecticidal properties) or lindane (high insecticidal properties) is being used with values more than one indicating technical $\mathrm{HCH}$, and values below one indicating lindane is being used [32].

\subsection{Defining land use categories}

Satellite images from Landsat 4 (1989), Landsat 7 (1999), Landsat 5 (2009) and Landsat 6 (2019) were used to estimate and classify land use land cover (LULC) classification. The satellite data was acquired from USGS: Earth Explorer for path169, row 60; path 168, row 61; path 169 , row 60 and path 169 row 61. Catchment delineation was done using ArcGIS Version 10.3. Sub-catchment delineation was performed using predetermined pour-points for sampling. LULC classification was performed using ENVI Version 5.1. Unsupervised classification was first performed using IsoData and K-Means algorithms with a set of 10 classes. The classes were then used to define regions of interest (ROIs) for supervised maximum likelihood classification. The classes selected were generated from unsupervised classification and from previous studies conducted in the area [33]. Training samples were then selected, and the LULC classes were divided into six types: open water, broadleaf evergreen forest, croplands, built-up, grasslands and bare soils/rocks. Change detection analysis was then carried out for the catchment and sub-catchments in ENVI 5.1 for three periods, 1989-1999, 1999-2009 and 2009-2019. These were used to demonstrate the probability of increased agricultural intensification in the catchment.

\subsection{Geospatial assessment for agricultural expansion}

The study defined agricultural expansion as a change on land use/cover classes associated with a reduction in forest cover [34], and increased cropland and grassland [35], [36]. An increase in the number of land use classes would suggest increased heterogeneity, while reduction in the land use classes indicate land use homogeneity. On the other hand, intensification was defined by a reduced forest area, increased cropland area, reduction in grassland area, and increase in bare soils/rocks. Intensification was apparent when the five indicators were true for the catchment, while it indicated semi-intensification when three to four of the indicators were true; semi extensive when two indicators were true; and extensive when only one of the indicators was true. Eq. 1 describes the agricultural expansion (AE) probability. 
$A E=$ Heterogeneity + Forestcover + Cropland + Grassland + Baresoil Eq. 1

Where $A E$ is cumulative score ( 5 = full intensification; $3-4=$ semi-intensification; 2 = semi-extensive; $1=$ extensive); Heterogeneity is 1 (otherwise 0 ) if the number of land use classes have increased; Forest cover is 1 (otherwise 0 ) if there is a reduction in proportion of broadleaf evergreen forest; Cropland is 1 (otherwise 0) if the there is an increase in the proportion of cropland; Grassland is 1 (otherwise 0) if there is an increase in proportion of grassland; and Bare soil is 1 (otherwise 0 ) if there is a reduction in proportion of bare soil.

\subsection{Relationship between land uses, nutrients and pesticide concentrations}

Using mixed model analysis, the study assessed the relationship between land cover categories and the concentration of total phosphorus, total nitrogen, $\sum \mathrm{DDT}, \sum \mathrm{HCH}$, and $\sum$ cyclodienes. The Ime4 function [37] was used to perform a linear mixed effect analysis of the relationship between various land use categories and concentrations of the nutrients and pesticides. Linear mixed models with random slopes and intercepts were reduced to the minimum adequate models using the step (model $\mathrm{x}$, direction = "both") function to remove autocorrelations. The reduced models and the complete models were compared using the anova function in $\mathrm{R}$ [38] for the concentrations to determine sensitivity. The random intercept model had lower Akaike's Information Criterion (AIC) compared with the random slopes and was adopted for relating the fixed and random effects.

The relationship between the concentrations of pesticides and nutrients, and the level of agricultural intensification was determined using multinomial logistic regression. The multinomial logistic regression was suitable considering that the outcome variable (level of intensification determined by Eq. 1) was nominal, as such, the relative risk ratio of the outcome was modeled as a linear combination of predictor variables (concentration of nutrients and pesticides).

\subsection{Risks associated with the combined concentrations}

The contamination risk was determined as the ratio between the measured in situ concentrations and published water quality standards for the preservation of aquatic life (Eq. 2). The water quality standard used for the calculation of the risk were as documented by the United States Environmental Protection Agency [39] reported to be the minimum effect concentrations, and the Kenya Water Regulations [40] maximum allowed effluent discharge for protection of aquatic life (more detail in Supplementary Table 3).

$\operatorname{Risk}_{i}=\frac{C_{i}}{S_{i}}$ Eq. 2

Where Risk ${ }_{i}$ is probability of effect (Risk) for each of the contaminants (i); $C_{i}$ is the in-situ concentration of contaminant $i$; and $S_{i}$ is the water quality standard for the protection of aquatic life.

The water quality risk map was constructed using the product of risk ratios determined for each contaminant (Eq. 3). A product less than 1 would indicate lower combined risk, while a product greater than 1 indicates higher negative risk potential (Table 1).

Riskcalculation $=\log _{10}\left(D D T_{r} \times \mathrm{HCH}_{r} \times\right.$ Cyclo $_{r} \times$ nitrogen $_{r} \times$ phosphorus $\left._{r} \times \mathrm{TSS}_{r}\right)$ Eq. 3

Where Risk calculation is classified as in table, $D D T_{r}$ is the site risk ratio for $\mathrm{DDT} ; \mathrm{HCH}_{r}$ is the site risk ratio for $\mathrm{HCH}$; $\mathrm{CyClo}_{r}$ is the site risk ratio for cyclodienes, nitrogen $_{r}$ is the site risk ratio for nitrogen; phosphorus $s_{r}$ is the site risk ratio for phosphorus; and $T S S_{r}$ is the site risk ratio for total suspended solids.

Table 1

Classification of water quality risk map ${ }^{1}$

\begin{tabular}{|c|c|c|}
\hline $\begin{array}{l}\text { Risk calculation } \\
\text { range }\end{array}$ & Risk description & Risk classification \\
\hline $\begin{array}{l}\text { Less than or equal } \\
\text { to } 0\end{array}$ & The ratios indicate the water quality status is within the standards for protection of water quality & Low ecological risk \\
\hline Between 0 and 1 & $\begin{array}{l}\text { The contamination is between one and ten times higher than the standards for protection of water } \\
\text { quality }\end{array}$ & Medium ecological risk \\
\hline Between 1 and 2 & $\begin{array}{l}\text { The contamination is between ten and } 100 \text { times higher than the standards for protection of water } \\
\text { quality }\end{array}$ & Medium ecological risk \\
\hline Between 2 and 3 & $\begin{array}{l}\text { The contamination is between } 100 \text { and } 1,000 \text { times higher than the standards for protection of water } \\
\text { quality }\end{array}$ & $\begin{array}{l}\text { Medium-High ecological } \\
\text { risk }\end{array}$ \\
\hline Between 3 and 4 & $\begin{array}{l}\text { The contamination is between } 1,000 \text { and } 10,000 \text { times higher than the standards for protection of } \\
\text { water quality }\end{array}$ & High ecological risk \\
\hline Between 4 and 5 & $\begin{array}{l}\text { The contamination is between } 10,000 \text { and } 100,000 \text { times higher than the standards for protection of } \\
\text { water quality }\end{array}$ & $\begin{array}{l}\text { High - Very high ecological } \\
\text { risk }\end{array}$ \\
\hline Above 5 & The contamination is above 100,000 higher than the standards for protection of water quality & Very high ecological risk \\
\hline \multicolumn{3}{|c|}{ Source: Authors of the paper } \\
\hline
\end{tabular}

\section{Results}




\subsection{Agricultural expansion in Lake Naivasha catchment}

Between 1989 and 2019, there was an increase of cropland by $623 \mathrm{~km}^{2}$, a reduction of forest cover by $200 \mathrm{~km}^{2}$, increase of grasslands by $534 \mathrm{~km}{ }^{2}$, a reduction in bare soils by $100 \mathrm{~km}^{2}$, and an increase of $540 \mathrm{~km}^{2}$ of built area, and a general increase of number of land uses (more detail in Supplementary Table 4). Figure 2 shows the decadal landuse changes from 1989 to 2019.

The MANOVA results show a significant difference in the land use/cover over time as a factor of the land use classifications $($ Pillai's Trace $=1.39, F(5,40)=$ $4.28, p<0.05)$. Moreover, univariate analyses suggest significant differences in land use/cover among the different sub-catchments, especially between those of the rivers Gilgil and Malewa $(F(8,199)=35.52, p<0.05)$, and among the different land use classes, especially between bare soils/rocks and the other land uses/cover classes $(F(5,199)=19.36, p<0.05)$. There is a probability of intensified expansion in the L. Naivasha catchment, ranging from potential full intensification at G1, to extensive agriculture in G3 in 2015 relative to 1989 (more detail in Supplementary Table 5). The results of the study indicate that lower river reaches tend towards extensive agricultural production systems, while upper and middle reaches are tending towards intensification.

\subsection{Distribution of nutrients and pesticides in aquatic ecosystems}

Increasing concentrations of nutrients from upstream to downstream in the rivers of the L. Naivasha catchment (Table 2), reflect cumulated loadings. The highest total phosphorus (TP) concentration $\left(1.6 \pm 0.2 \mathrm{mg} . \mathrm{L}^{-1}\right)$ was recorded within the Karati River (K1 - Karati highway) and the lowest $\left(42 \pm 3 \mu \mathrm{g} . \mathrm{L}^{-1}\right)$ within L. Naivasha (N3 - Hippo Point). The highest TP concentrations were recorded in the sequence R. Karati $>$ R. Malewa $>$ R. Gilgil $>$ L. Naivasha, with significant differences among sites (Kruskal-Wallis chi-squared test $=85.30, \mathrm{df}=12, \mathrm{p}<0.05$ ), and notably between the rivers and lake sites, and between $\mathrm{K} 1$ and the upper reaches of the R. Gilgil (G1 - Kahuho, G2 - Little Gilgil) and R. Malewa (M1 and M2 - upper Malewa. The highest recorded total nitrogen (TN) concentration was found at K1 $\left(2.6 \pm 0.6 \mathrm{mg} . \mathrm{L}^{-1}\right)$, while the lowest $\left(0.5 \pm 0.1 \mathrm{mg} \cdot \mathrm{L}^{-1}\right)$ at M2. The highest TN concentrations were recorded in the sequence R. Karati $>$ R. Gilgil $>$ R. Malewa $>$ L. Naivasha, with significant differences among the sites (Kruskal-Wallis chi-square test $=26.64, \mathrm{df}=12, \mathrm{p}<0.05$ ), notably between the river and the lake sites.

Table 2

Concentration (mean \pm SE) of nutrients and pesticides recorded in L.ake Naivasha catchment within the study sites ( $n=16$ samples per site).

\begin{tabular}{|c|c|c|c|c|c|c|}
\hline \multirow[t]{3}{*}{ Sub-catchment } & \multirow[t]{3}{*}{ Site } & \multicolumn{2}{|c|}{ Nutrient Concentrations } & \multicolumn{3}{|c|}{ Pesticide residues concentrations } \\
\hline & & TN & TP & $\sum \mathrm{DDT}$ & $\sum \mathrm{HCH}$ & $\sum$ Cyclodienes \\
\hline & & $\left(\mu \mathrm{g} \cdot \mathrm{L}^{-1}\right)$ & $\left(\mu \mathrm{g} \cdot \mathrm{L}^{-1}\right)$ & (ng. $\mathrm{L}^{-1}$ ) & (ng. $\mathrm{L}^{-1}$ ) & (ng. $\mathrm{L}^{-1}$ ) \\
\hline River Karati & $\mathrm{K} 1$ & $2554 \pm 574$ & $1551 \pm 179$ & $94 \pm 16$ & $135 \pm 57$ & $1487 \pm 173$ \\
\hline \multirow[t]{3}{*}{ River Gilgil } & G1 & $1296 \pm 332$ & $140 \pm 29$ & $278 \pm 73$ & $33 \pm 4$ & $1699 \pm 489$ \\
\hline & $\mathrm{G} 2$ & $835 \pm 193$ & $127 \pm 19$ & $175 \pm 40$ & $187 \pm 81$ & $1383 \pm 276$ \\
\hline & G3 & $1389 \pm 339$ & $244 \pm 56$ & $338 \pm 73$ & $82 \pm 17$ & $256 \pm 3$ \\
\hline \multirow[t]{5}{*}{ River Malewa } & M1 & $1035 \pm 122$ & $138 \pm 27$ & $269 \pm 44$ & $141 \pm 64$ & $989 \pm 207$ \\
\hline & M2 & $521 \pm 97$ & $326 \pm 98$ & $157 \pm 34$ & $98 \pm 21$ & $738 \pm 123$ \\
\hline & M3 & $1664 \pm 510$ & $594 \pm 181$ & $163 \pm 39$ & $51 \pm 8$ & $618 \pm 115$ \\
\hline & M4 & $872 \pm 167$ & $409 \pm 110$ & $168 \pm 20$ & $99 \pm 22$ & $392 \pm 78$ \\
\hline & M5 & $1464 \pm 380$ & $502 \pm 154$ & $264 \pm 82$ & $91 \pm 20$ & $1588 \pm 404$ \\
\hline \multirow[t]{4}{*}{ Lake Naivasha } & $\mathrm{N} 1$ & $695 \pm 158$ & $164 \pm 47$ & $294 \pm 71$ & $260 \pm 102$ & $1762 \pm 278$ \\
\hline & N2 & $497 \pm 138$ & $51 \pm 5$ & $210 \pm 65$ & $159 \pm 64$ & $1209 \pm 66$ \\
\hline & N3 & $597 \pm 163$ & $42 \pm 3$ & $377 \pm 140$ & $238 \pm 89$ & $3481 \pm 440$ \\
\hline & N4 & $563 \pm 153$ & $47 \pm 3$ & $352 \pm 125$ & $186 \pm 68$ & $1916 \pm 354$ \\
\hline
\end{tabular}

The concentrations for pesticides recorded comprised the $\sum$ DDT group (p,p-DDT, p,p-DDE and p,p-DDD), $\sum$ HCH group (alpha, beta, delta and gamma), and $\sum$ cyclodienes group (aldrin and derivative dieldrin; heptachlor and derivative heptachlor epoxide; endrin and its derivative endrin aldehyde; endosulfan group comprising alpha, beta and endosulfan sulphate; and methoxychlor), summarised in Table 2. The highest concentration of $\sum$ DDT was recorded in the sequence L. Naivasha > R. Gilgil > R. Malewa > R Karati. The concentrations $\sum$ HCH ranged between $33 \pm 4$ ng.L-1 (at G1) and $260 \pm 102$ ng.L L $^{-1}$ (at N1), with the highest concentrations of $\sum \mathrm{HCH}$ was recorded in the sequence L. Naivasha > R. Karati > R. Gilgil > R. Malewa. The lowest concentration of $\sum \mathrm{HCH}$ was recoded from G1 (Kahuho). The $\sum$ cyclodienes ranged between $256 \pm 3$ ng. $\mathrm{L}^{-1}$ at G3 (R. Gilgil Highway Bridge) and $3.5 \pm 0.4 \mu \mathrm{g} . \mathrm{L}^{-1}$ at N3 (Hippo point). The highest concentrations of $\sum$ cyclodienes were recorded in the sequence L. Naivasha > R. Gilgil > R. Malewa > R. Karati. However, there was no significant difference among the sites for the pesticide groups.

The study found out that the concentrations of nutrients (total phosphorus and nitrogen) were not significant predictors of the concentrations of pesticides ( $\sum$ DDT, $\sum \mathrm{HCH}$ and $\sum$ cyclodienes) in the L. Naivasha catchment (Table 3). 
Table 3

Linear regression results between the concentration of nutrients and pesticides in the Lake Naivasha catchment.

\begin{tabular}{|lllll|}
\hline Pesticide residues & \multicolumn{2}{l}{ Total Nitrogen } & \multicolumn{2}{l|}{ Total Phosphorus } \\
\cline { 2 - 5 } & Coefficient $^{1}$ & Statistics & Coefficient & Statistics \\
\hline$\sum$ DDT & $-0.04 \pm 0.02^{*}$ & $F(1,89)=4.28, p<0.05, R^{2}=4 \%$ & $-0.07 \pm 0.04$ & $F(1,86)=2.13, p=0.15, R^{2}=1 \%$ \\
\hline$\sum \mathrm{HCH}$ & $0.02 \pm 0.01$ & $F(1,121)=3.50, p=0.06, R^{2}=2 \%$ & $-0.04 \pm 0.04$ & $F(1,118)=1.27, p=0.26, R^{2}=0 \%$ \\
\hline$\sum$ Cyclodienes & $-0.08 \pm 0.19$ & $F(1,46)=0.17, p=0.68, R^{2}=0 \%$ & $-0.44 \pm 0.34$ & $F(1,45)=1.74, p=0.19, R^{2}=1 \%$ \\
\hline 1 - coefficient \pm Standard Error & & & \\
\hline
\end{tabular}

\subsection{Potential implication of nutrient and pesticide concentrations to aquatic ecology in Lake Naivasha Catchment}

The TN/TP ratio findings in this study, associated the upper reaches of Gilgil River (at G1 and G2) and the Hippo point (N3) sites, with extensive crop cover from small scale farming (Table 4). In addition, the TN/TP ratios indicated potential phosphorus limitation in the three sites, and application of nitrogen-based crop fertilizers.

Table 4

Inference ratios for pesticides and nutrients in Lake Naivasha catchment.

\begin{tabular}{|c|c|c|c|c|c|}
\hline Site & DDD:DDE & (DDE + DDD):DDT* & DDT:DDE** & TN:TP & a:Y-HCH \\
\hline K1 & 0.58 & 0.1 & 11.07 & 2 & $0.8^{c}$ \\
\hline G1 & $1.75^{\mathrm{b}}$ & 0.1 & 19.51 & $21^{a}$ & $0.76^{\mathrm{c}}$ \\
\hline G2 & $1.88^{\mathrm{b}}$ & 0.2 & 15.72 & $17^{a}$ & $0.49^{c}$ \\
\hline G3 & 0.87 & 0.5 & 4.02 & 11 & $0.71^{\mathrm{c}}$ \\
\hline M1 & 2.49 & 0.3 & 12.45 & 11 & $1.43^{d}$ \\
\hline M2 & 0.55 & 0.2 & 6.9 & 5 & $1.02^{d}$ \\
\hline M3 & 0.95 & 0.2 & 8.03 & 7 & $0.77^{\mathrm{c}}$ \\
\hline M4 & $1.27^{\mathrm{b}}$ & 0.2 & 13.95 & 12 & $1.15^{\mathrm{d}}$ \\
\hline M5 & $1.91^{\mathrm{b}}$ & 0.3 & 8.86 & 6 & $0.28^{c}$ \\
\hline N1 & 0.94 & 0.3 & 6.42 & 6 & $0.24^{\mathrm{c}}$ \\
\hline N2 & 0.78 & 0.2 & 8.58 & 11 & $0.18^{\mathrm{c}}$ \\
\hline N3 & 0.63 & 0.2 & 6.82 & $18^{a}$ & $0.32^{\mathrm{c}}$ \\
\hline N4 & 2.27 & 0.5 & 7.17 & 11 & $0.17^{c}$ \\
\hline \multicolumn{6}{|c|}{ a - areas of extensive crop cover, and application of nitrogen-based fertilizers } \\
\hline \multicolumn{6}{|c|}{ b - areas of anaerobic DDT degradation } \\
\hline \multicolumn{6}{|c|}{$c$ - use of lindane with higher insecticidal effect } \\
\hline \multicolumn{6}{|c|}{$\mathrm{d}$ - use of technical $\mathrm{HCH}$ with lower insecticidal effects } \\
\hline \multicolumn{6}{|c|}{ * - values indicate source of DDT is not from long term weathering } \\
\hline ** - & lues indicat & recent DDT applicati & & & \\
\hline
\end{tabular}

The DDD:DDE ratio was highest in the upper reaches of Gilgil River (1.75-1.88) and the lower reaches of the Malewa River (1.27-1.91). In the L. Naivasha sites, the DDD:DDE ratio was the lowest (ratio range). This suggests that DDT degradation was anaerobic in the rivers (sediments in the pools) and aerobic (pelagic) in the lake. The ratio of (DDE + DDD):DDT recorded ranged between 0.1 and 0.5 , an indication that the DDT is not from long term weathering of soils into the water ecosystem. Further, the DDT:DDE ratio recorded at all the sites were above 0.33 , indicating recent use of pesticides with DDT as active ingredients. The a: $\mathrm{y}-\mathrm{HCH}$ ratios were more than one in the upper and mid reaches of the Malewa River, an indication of the use technical $\mathrm{HCH}$ with lower insecticidal potential, while in the Gilgil River and the Lake sites showed ratios of below one, indicating use of lindane, with higher insecticidal effects. The L. Naivasha sites showed the lowest a: $\mathrm{Y}-\mathrm{HCH}$ ratios suggesting higher use of lindane in the area. 


\subsection{Agricultural intensification in relation to nutrient and pesticide contamination}

In the study, the potential effect of land use/cover changes indicate various scenarios. For example, increasing forest cover, could potentially reduce contamination from nutrients (TP and TN), while increasing pesticide residues ( $\sum$ DDT, $\sum \mathrm{HCH}$ and $\sum$ cyclodienes) within the surface water of the L. Naivasha catchment (Table 5). The relationship between agricultural expansion and concentration of nutrients and pesticides indicated differing influences of land use and intensification on pesticide and nutrient concentrations (more detail in Supplementary Table 6). On one hand, the findings indicate that a relatively natural ecosystem would have lower concentrations of TP, and $\sum D D T$, and a higher concentration of TN compared with an extensive system. On the other hand, full intensified systems also show lower concentrations of TP, and $\sum$ DDT, compared with extensive systems. This suggests that counter intuitively, extensive systems are contributing more to the concentration of nutrients and pesticides in aquatic systems than the intensive landuse.

\subsection{Nutrient and pesticide risks to aquatic ecosystem}

For all except the Karati Highway site (K1), the concentrations of $\sum$ DDT and $\sum$ cyclodienes found in the surface waters of the L. Naivasha catchment exceed 100 times (more detail in Supplementary Table 2) the water quality standards recommended by US EPA [39]. The total nitrogen concentrations were modest across all sites according to the USEPA, and lower than the water quality standards provided for Kenya - except for K1. However, total phosphorus concentrations ranged from high to extremely high for river waters, and below requisite concentrations for protection of aquatic life (with reference to both the USEPA and Kenya Water Quality Standards). While the risk of pesticides ( $\sum$ DDT and $\sum$ cyclodienes) to aquatic life was lower in K1, the site had high concentrations of TP. In general, the lake showed the lowest risk ratios, while Malewa River catchment showed the highest risk ratios.

The water quality risk map (presented in Fig. 3) based on criteria shown in Table 1, indicates that most of the lower reaches of the rivers (Gilgil, Malewa and Karati), tend towards poor status for the five pollutants (TN, TP, $\sum$ DDT, $\sum \mathrm{HCH}$ and $\sum$ cyclodienes) recorded in the study. The approach taken towards development of the water risk map, does not take into consideration the land use changes, which may present a limitation to the study. However, as a management tool, the risk map presents catchment managers with an entry point on water quality management with respect to combined nutrients and pesticides in L. Naivasha catchment.

Table 5

Potential effects of land use/cover on the concentration of nutrients and pesticides

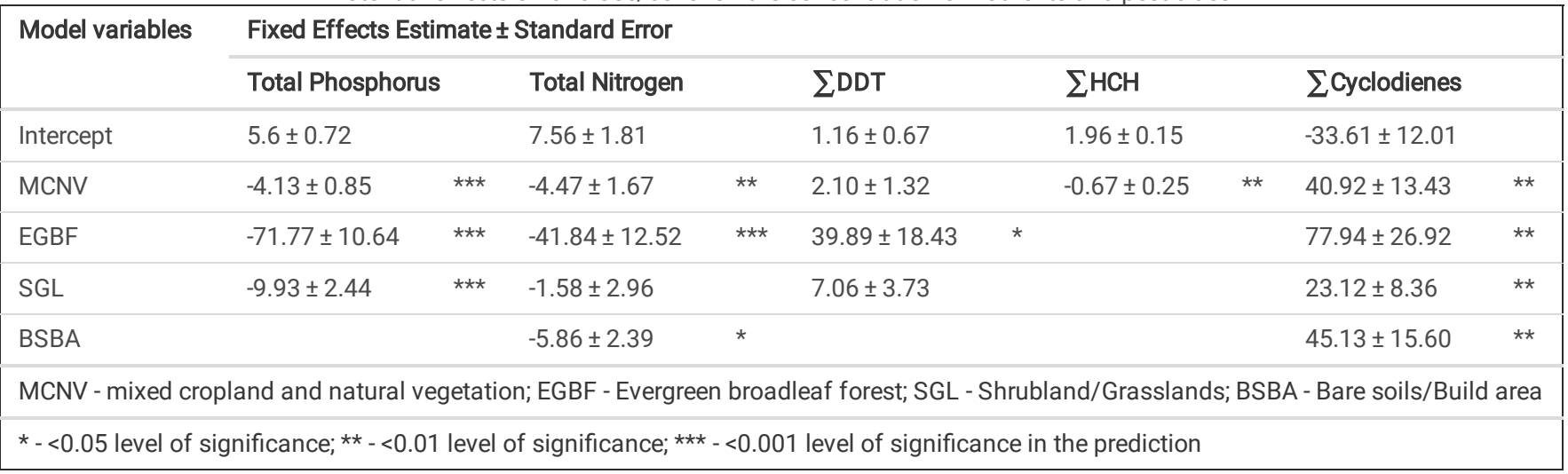

\section{Discussion}

\subsection{Agricultural intensification and contamination in Lake Naivasha catchment}

Based on the secondary geospatial assessment, there has been an expansion of intensified agriculture in the L. Naivasha catchment[34]-[36]. Agricultural intensification between 1989 and 2019 in the L. Naivasha catchment suggests dynamic landscape changes, leading to contamination of surface waters. At the same time, lower river reaches have tended towards extensive agricultural production systems, while upper and middle reaches have tended towards intensification. The population changes in the upper reaches of L. Naivasha catchment [18], [41], and subsequent land subdivisions for small scale farming are possible explanations of intensification potential [20]. Boserup (1965) postulated increased population density promotes agricultural intensification, with higher densities (above 600 persons per $\mathrm{km}^{2}$ ) resulting in unsustainable intensification [7]. The implication of this is the degradation of the landscape in the catchment as a result of agricultural expansion [33], [42]. Considering that increased forest and shrub cover enhances evapotranspiration, while increased bare land enhances surface water release, thus, increased bare land can have a negative impact on both water quality and quantity through sediment and pollutant emissions to surface waters [42]. Further, intensification in the upper reaches suggest that agricultural activities would be the main source of agrochemicals [43], transported to L. Naivasha, highlighting the need to understand the spatial distribution of nutrients and pesticides in the catchment.

While the distribution of nutrient concentration in the catchment is likely to be a consequence of diffuse sources from land-use, the significantly higher nutrient concentrations at K1 (River Karati Highway Bridge) suggest higher point-source contribution from extensive agricultural farms around the site. The particular (K1) site has been documented by previous studies to show high concentrations of heavy metals [44], [45], and nutrients [46], [47] which indicates potential negligent use of agrochemicals. Although Everard et al. [48] argue that the geological difference between the Karati River sub-catchment and the other river sub-catchments could explain the high chemical contamination at K1, the consistently higher concentrations at the site, indicates anthropogenic, point-source pollution. This study established that within the lake, the river mouth site (N1 - River Mouth) acts as major source of pollution into the lake, registering higher concentrations of nutrients compared with the other sites in the lake. Although similar trend of results within the lake have been reported, the current study

Page $7 / 15$ 
recorded three times higher concentrations of total phosphorus compared with Kitaka et al. [49] and $10 \%$ higher total nitrogenthan recorded by Ndungu et al. [50]. The relatively lower concentrations of total nitrogen and phosphorus in lakes compared with rivers is consistent with both dilution and settling effects [51], [52], making L. Naivasha a sink for the nutrients accumulated from the rivers, a concept that was first documented by Vollenweider and Kerekes [53].

Although DDT is banned in Kenya, except for use by public health officials [54], its presence in high concentration in surface waters of the L. Naivasha catchment, and the subsequent high DDT:DDE ratios across the catchment indicate recent and continued use. The $\sum$ DDT was highest in the lake samples, indicating that the lake is also a sink of DDT used in the catchment. The persistence of DDT in sediments could also indicate potential resuspension from the sediments [55], as well as the higher distribution potential of DDT compared with $\mathrm{HCH}$ or cyclodienes [28]. $\sum \mathrm{HCH}$ was highest in the lake, which supports the findings by Onyango et al.,[54], [56] that there is continued application of technical lindane around the lake. While the concentrations reported in this study are within range of earlier studies by Onyango et al., [56], it is up to $700 \%$ higher than the values recorded in L. Naivasha by Njogu [57]. The concentrations of $\sum$ cyclodienes were highest in the lake sites, with the main river source of the cyclodienes being River Gilgil, and lower reaches of River Malewa. The distribution of the cyclodienes within the lake showed high concentrations within the deeper parts of the main lake (M3 - Hippo point) which has been documented by Ndungu et al.[22] and Outa et al.[58] as an area of lower disturbance. Further, the current study reports higher concentrations of cyclodienes compared with those reported by Gitahi et al. [59], suggesting continuous increase in use of cyclodienes based pesticides.

Despite that there was no significant relationship between the contamination by pesticides and enrichment of nutrients across the sites, it would be expected that agricultural intensification involved concurrent use of nutrients and pesticides [6], [60], and reflected in a correlation between occurrence and concentrations. However, differences in modes of action between nutrients and pesticides (Bainbridge et al., 2009; Damalas and Eleftherohorinos, 2011; EU, 2011) and the pathways of transfer to aquatic sources [64], [65] would explain the absence of correlation between nutrients and pesticide concentrations in L. Naivasha catchment.

\subsection{Implication of agricultural intensification in relation to aquatic ecology}

Rattan \& Chambers [66] argued that TN:TP stoichiometry was positively correlated with crop cover, associating agricultural land use and TN:TP ratios. On the other hand, the majority of the sites indicated a potential nitrogen limitation, but increased application of phosphorus-based fertilizers [27], [67], [68]. There is continued use of DDT and technical HCH in the catchment, with consequent emissions to both the river sediments and lake water.

Evidence of increased pesticide residues in the forest areas are comparable with the higher concentration of DDT reported by Onyango et al. [54] within the upper reaches of the R. Malewa sub-catchment. Odongo et al. [18] and van Oel et al [33] argue that increasing forest cover is negatively related to proportion of agricultural land, leading to expected lower anthropogenic input of nutrients and pesticides into the aquatic ecosystem. However, forested areas in the $L$. Naivasha catchment are associated with fragmented, and small scale, intensified agricultural production, which could explain the increased pesticide concentrations, particularly through point sources in the forested areas. On the other hand, extensive systems can be associated with agricultural expansion without sustainability safeguards [69], especially in many of the catchments in sub-Saharan Africa with little to no strategic catchment management strategies. In the L. Naivasha catchment, increased and emission of nutrients and pesticides indicates, unsustainable intensification/expansion, with potential impact on biodiversity [70]. An overview would be that it is a fragmented landscape, with trends of reduced forest cover and grassland, and increased crop production. The net result is increased diffuse fertiliser and pesticides pollution. This suggests the need to apply agricultural extension services to better manage sustainable intensification, with the goal to reduce overall agrochemical contamination [5], [35], coupled with improved monitoring of the use of inputs in catchments, and consideration of precision farming practices [71].

Integrated monitoring of nutrient and pesticide concentrations in surface waters and their association with LULC is a major need for development of policies and to support water and land management in many African catchments subject to intensification, or where plans are developing for intensification for food security and economic development [7]. Achieving that without moving beyond environmentally safe limits with longer term impact on land productivity, ecosystem integrity and public health is a major challenge [72]. When catchments include protected areas, or sites that have been designated under international agreement such as is the case for L. Naivasha as designated Ramsar site the balancing act of environmental protection can be even more difficult.

\subsection{Management of agricultural intensification}

The study identified excess recent and continued inputs of pollutants from agriculture to the surface waters of the L. Naivasha catchment as a management gap. This includes potential impact from banned pesticides used across the catchment; land use changes with complementary intensification practices; and high to very high risk of combined nutrients and pesticides chemical pollution in surface waters. These risks occur across many agricultural catchments in sub-Sahara Africa (SSA) [1], [73]-[75]. Standards for managing aquatic resources are highlighted in the Africa Water Vision 2025 [76] advocating for a revision of water regulations and laws to give attention to water quality management. However, the blueprint ignores the potential of ecosystem-based management to allow land-use based water quality management and allocates only $3 \%$ of the annual investment (USD 0.6 billion) to institutional and policy reforms, and research and development. Based on the findings in this study, the revision of the Africa Water Vision 2025 needs to take into consideration water quality standards that incorporate combined nutrients and pesticide use and their emissions from land to water.

Kenya's regulations on water quality standards [77] does not consider the potential of combined effects of nutrients and pesticide, neither does it consider monitoring, review, and policing framework for banned substances in surface waters. Moreover, the standards do not have provisions to monitor effluents associated with banned pesticides. This is a clear indication on mismatch between regulation, and enforcement, that requires the responsible agencies including the Water Resources Authority (WRA), National Environment Management Authority (NEMA), and the Kenya Bureau of Standards (KEBS) to actively revise the water quality standards, enforce the management of the standards, and invest in policy and institutional reforms to address management of agricultural intensification. 
Policy and institutional reforms contributing to development of regulations that consider the increased risks to surface water and promotes enforcement for compliance to the regulations can provide considerable benefits for sub-Saharan Africa agricultural management. Examples for action include investment from nutrient credit trading, payment for environmental services, innovating financing, and financial instruments [78]. Partnerships among national and subnational governments and the private sector can include more focus on the monitoring of aquatic resources through definition of indicators combining biological, physical, and chemical monitoring [79]. Further, the partnerships can promote coherence of regulations across jurisdictions, and coordination among strategic water quality management and policy authorities. Catchment management partnerships - such as Imarisha in Naivasha [80], have an opportunity for inclusive and integrated management. At the same time, a monitoring regime which will require availability of consistent and continuous water quality data, to track and document progress in the development of water resources regulations and policy[81]. The water quality guidelines in Kenya provides for frequency of monitoring, single chemical and biological standards, methodologies for collection and analysis of samples, and a reporting framework [40]. However, the standards do not take into consideration combined contamination.

The study shows that intensification, accompanied by increased application of nutrients and pesticides [11], needs sustained advisory capacity in the use of agricultural inputs [60]. However, the capacity and resources to manage the advisory services are still underdeveloped in Kenya, as in many sub-Saharan African countries. Reviewing the water quality standards taking into consideration combined contamination would need the integration of advisory platforms, including online advisory, that controls the emissions of pollutants to surface waters. Inadequate resources to manage advisory services, is exacerbated by inadequate standardized monitoring methodologies. The United Nations Environment Programme [82] in its Progress on Ambient Water Quality update, report findings from methodological considerations for monitoring water quality. However, the report recommends that the monitoring of ambient water quality should use national and/or subnational water quality standards. In many SSA countries, the standards are not comprehensive, a situation that reinforces the need for integrated review for water pollution management at national level.

An integrated review of standards would contribute to achieving and compliance with the Sustainable Development Goals (SDGs) including: SDG 2 through promotion of sustainable agriculture practices, SDG 14 through reduction of risks to aquatic biota, SDG 3 through reducing the potential of health complications from exposure to contaminants in the aquatic systems, SDG 6 through availing better water quality and promoting sanitation, and SDG 17 through promoting inclusive partnerships for monitoring and review. Further SDG indicator 6.3.2, provides a mechanism for determining whether, and to which extent, water quality management is successful, with a target to increase the proportion of water bodies with good water quality [82]. The findings from this study, emphasizes the need for water quality managers to consider combined contamination from nutrients and pesticides, and how that is monitored.

\section{Conclusions}

The transformation of the L. Naivasha landscape suggest unsustainable agricultural expansion with fragmented land use/cover, reduced forest cover and grasslands, and increased croplands. This scenario is common in agricultural catchments in sub-Sahara Africa, where forests and grasslands are cleared and replaced by agricultural production of crops and use by livestock. The expansion is linked strongly to increased emissions of nutrients and pesticides to aquatic resources in the catchment, resulting in pollution loads, exceeding legal limits. L. Naivasha catchment is not an exemption to this, and this study has demonstrated recent and continued pesticide contamination of highly persistent DDT (and its degradates 'DDE and DDD). Further, the nutrients enrichment status in the catchment, compared with historical reported enrichment, indicate a catchment that is highly eutrophic. These are clear indicators of a catchment with agricultural practices leading to negative combined nutrients and pesticides impact. The catchment exemplifies problems that are widespread across sub-Sahara Africa in attempts to promote food security and economic development.

Achieving sustainable catchment management needs the inclusion of combined pollutants as a variable in management. Since this is an emerging topic of importance in sub-Saharan Africa, the study highlights the need to adopt practices that support water quality regulators and catchment managers to achieve the SDGs.

\section{Data Availability}

All data generated or analysed during this study are included in this published article and its supplementary information files.

\section{References}

1. M. Abberton et al., "Global agricultural intensification during climate change: a role for genomics," Plant Biotechnology Journal, vol. 14, no. 4, pp. 10951098, Apr. 2016, doi: 10.1111/pbi.12467.

2. L. V. Rasmussen et al., "Social-ecological outcomes of agricultural intensification," Nature Sustainability, vol. 1, no. 6, pp. 275-282, 2018, doi: 10.1038/s41893-018-0070-8.

3. B. Phalan, M. Onial, A. Balmford, and R. E. Green, "Reconciling Food Production and Biodiversity Conservation: Land Sharing and Land Sparing Compared," Science, vol. 333, no. 6047, pp. 1289 LP - 1291, Sep. 2011, doi: 10.1126/science.1208742.

4. E. D. Roy et al., "The phosphorus cost of agricultural intensification in the tropics," Nature Plants, vol. 2, no. 5, p. 16043, 2016, doi: 10.1038/nplants.2016.43.

5. R. P. Nijbroek and S. J. Andelman, "Regional suitability for agricultural intensification: a spatial analysis of the Southern Agricultural Growth Corridor of Tanzania," International Journal of Agricultural Sustainability, vol. 14, no. 2, pp. 231-247, Apr. 2016, doi: 10.1080/14735903.2015.1071548.

6. G. Nziguheba et al., "Phosphorus in smallholder farming systems of sub-Saharan Africa: implications for agricultural intensification," Nutrient Cycling in Agroecosystems, vol. 104, no. 3, pp. 321-340, 2016, doi: 10.1007/s10705-015-9729-y. 
7. D. K. Willy, M. Muyanga, and T. Jayne, "Can economic and environmental benefits associated with agricultural intensification be sustained at high population densities? A farm level empirical analysis," Land Use Policy, vol. 81, pp. 100-110, Feb. 2019, doi: 10.1016/J.LANDUSEPOL.2018.10.046.

8. M. Sheahan, C. B. Barrett, and C. Goldvale, "Human health and pesticide use in Sub-Saharan Africa," Agricultural Economics, vol. 48, no. S1, pp. 27-41, Nov. 2017, doi: 10.1111/agec.12384.

9. S. T. Holden, "Fertilizer and sustainable intensification in Sub-Saharan Africa," Global Food Security, vol. 18, pp. 20-26, Sep. 2018, doi: 10.1016/J.GFS.2018.07.001.

10. G. W. Sileshi et al., "Nutrient use efficiency and crop yield response to the combined application of cattle manure and inorganic fertilizer in sub-Saharan Africa," Nutrient Cycling in Agroecosystems, vol. 113, no. 2, pp. 181-199, 2019, doi: 10.1007/s10705-019-09974-3.

11. M. Sheahan and C. B. Barrett, "Ten striking facts about agricultural input use in Sub-Saharan Africa," Food Policy, vol. 67, pp. 12-25, Feb. 2017, doi: 10.1016/J.FOODPOL.2016.09.010.

12. C. Nellemann et al., "Globio global methodology for mapping human impacts on the biosphere," Development, p. 55, 2001.

13. J. Salgado et al., "Eutrophication homogenizes shallow lake macrophyte assemblages over space and time," Ecosphere, vol. 9, no. 9, Sep. 2018, doi: $10.1002 /$ ecs2.2406.

14. Y. Zhang et al., "Nutrient enrichment homogenizes taxonomic and functional diversity of benthic macroinvertebrate assemblages in shallow lakes," Limnology and Oceanography, vol. 64, no. 3, pp. 1047-1058, May 2019, doi: 10.1002/Ino.11096.

15. I. Mahmood, S. R. Imadi, K. Shazadi, A. Gul, and K. R. Hakeem, “Effects of pesticides on environment," in Plant, Soil and Microbes: Volume 1: Implications in Crop Science, 2016. doi: 10.1007/978-3-319-27455-3_13.

16. M. G. Park, E. J. Blitzer, J. Gibbs, J. E. Losey, and B. N. Danforth, "Negative effects of pesticides on wild bee communities can be buffered by landscape context," Proceedings of the Royal Society B: Biological Sciences, vol. 282, no. 1809, Jun. 2015.

17. J. L. Awange et al., "Understanding the decline of water storage across the Ramser-Lake Naivasha using satellite-based methods," Advances in Water Resources, 2013, doi: 10.1016/j.advwatres.2013.07.002.

18. V. O. Odongo et al., "Coupling socio-economic factors and eco-hydrological processes using a cascade-modeling approach," Journal of Hydrology, vol. 518, no. PA, pp. 49-59, Jan. 2014, doi: 10.1016/j.jhydrol.2014.01.012.

19. P. R. van Oel et al., "The Effects of Groundwater and Surface Water Use on Total Water Availability and Implications for Water Management: The Case of Lake Naivasha, Kenya," Water Resources Management, vol. 27, no. 9, pp. 3477-3492, Jul. 2013, doi: 10.1007/s11269-013-0359-3.

20. D. K. Willy, E. Zhunusova, and K. Holm-Müller, "Estimating the joint effect of multiple soil conservation practices: A case study of smallholder farmers in the Lake Naivasha basin, Kenya," Land Use Policy, vol. 39, pp. 177-187, 2014, doi: 10.1016/j.landusepol.2014.02.017.

21. M. C. G. Clarke, Geological, volcanological and hydrogeological controls on the occurrence of geothermal activity in the area surrounding Lake Naivasha, Kenya: with coloured 1: 250000 geological maps. 1990. doi: 10.1093/petrology/egp049.

22. J. Ndungu, D. C. M. Augustijn, S. J. M. H. Hulscher, B. Fulanda, N. Kitaka, and J. M. Mathooko, "A multivariate analysis of water quality in Lake Naivasha, Kenya," Marine and Freshwater Research, vol. 66, no. 2, pp. 177-186, 2015, doi: 10.1071/MF14031.

23. V. O. Odongo, "How climate and land use determine the hydrology of lake Naivasha basin," 2016. doi: 10.3990/1.9789036542333.

24. M. M. Mekonnen, A. Y. Hoekstra, and R. Becht, "Mitigating the Water Footprint of Export Cut Flowers from the Lake Naivasha Basin, Kenya," Water Resources Management, vol. 26, no. 13, pp. 3725-3742, Sep. 2012, doi: 10.1007/s11269-012-0099-9.

25. APHA, "Standard Methods for the Examination of Water and Wastewater, 22nd edition," American Public Health Association, American Water Works Association, Water Environment Federation, 2012, doi: 10.1520/E0536-16.2.

26. A. D. Abong'o, O. W. Shem, O. J. Isaac, O. M. Vincent, and K. Henrik, "Impacts of Pesticides on Human Health and Environment in the River Nyando Catchment, Kenya," International Journal of Humanities, Arts, Medicine and Sciences, vol. 2, no. 3, pp. 1-14, 2014, [Online]. Available: https://www.divaportal.org/smash/get/diva2:708839/FULLTEXT01.pdf

27. N. H. They, A. M. Amado, and J. B. Cotner, "Redfield Ratios in Inland Waters: Higher Biological Control of C:N:P Ratios in Tropical Semi-arid High Water Residence Time Lakes ," Frontiers in Microbiology , vol. 8. p. 1505, 2017. [Online]. Available:

https://www.frontiersin.org/article/10.3389/fmicb.2017.01505

28. A. el Nemr, A. A. Moneer, A. Khaled, and A. El-Sikaily, "Contamination and risk assessment of organochlorines in surface sediments of Egyptian Mediterranean coast," Egyptian Journal of Aquatic Research, vol. 38, no. 1, pp. 7-21, 2012, doi: 10.1016/j.ejar.2012.08.001.

29. G. Zhang, Y. S. Min, B. X. Mai, G. Y. Sheng, J. M. Fu, and Z. S. Wang, "Time trend of BHCs and DDTs in a sedimentary core in Macao Estuary, Southern China," in Marine Pollution Bulletin, 1999, vol. 39, no. 1-12, pp. 326-330. doi: 10.1016/S0025-326X(99)00010-7.

30. ATSDR, “Toxicological Profile for DDT, DDE, and DDD," in ATSDR's Toxicological Profiles, 2002. doi: 10.1201/9781420061888_ch69.

31. T. M. Tavares, M. Beretta, and M. C. Costa, "Ratio of DDT/DDE in the All Saints Bay, Brazil and its use in environmental management," in Chemosphere, Mar. 1999, vol. 38, no. 6, pp. 1445-1452. doi: 10.1016/S0045-6535(98)00546-3.

32. J. Vijgen, L. F. Yi, M. Forter, R. Weber, and R. Lal, "The legacy of lindane and technical HCH production," Organohalogen Compounds, vol. 68, no. November, pp. 899-904, 2006, [Online]. Available:

https://www.researchgate.net/profile/Rup_Lal/publication/267410840_The_legacy_of_lindane_and_technical_HCH_production/links/54ab68b30cf25c4c4

33. P. R. van Oel et al., "Supporting IWRM through spatial integrated assessment in the Lake Naivasha basin, Kenya," International Journal of Water Resources Development, vol. 30, no. 3, pp. 605-618, 2014, doi: 10.1080/07900627.2014.920248.

34. W. Sun, "A GIS-based integrated approach to explore land-use/cover change dynamics in south-central Indiana," 2006. 
35. L. C. P. Dias, F. M. Pimenta, A. B. Santos, M. H. Costa, and R. J. Ladle, "Patterns of land use, extensification, and intensification of Brazilian agriculture," Global change biology. 2016. doi: 10.1111/gcb.13314.

36. J. D. B. Gil, "Land use change, agricultural intensification and low-carbon agricultural practices in Mato Grosso, Brazil," 2017. [Online]. Available: http://opus.uni-hohenheim.de/volltexte/2017/1300

37. D. Bates, M. Mächler, B. Bolker, and S. Walker, "Fitting Linear Mixed-Effects Models Using Ime4," Journal of Statistical Software, 2015, doi: 10.18637/jss.v067.i01.

38. J. M. Chambers and T. J. Hastie, Statistical models in S. 2017. doi: 10.1201/9780203738535.

39. US EPA, "Water Quality Standards handbook," Water Quality Standards Hand Book -chapter 3, 2014, doi: EPA 820-B-14-008.

40. WASREB, “GUIDELINES ON DRINKING WATER QUALITY AND EFFLUENT MONITORING,” Nairobi, Kenya, 2008. [Online]. Available: https://wasreb.go.ke/downloads/Water_Quality_\&_Effluent_Monitoring_Guidelines.pdf

41. G. E. Otiang'a-Owiti and I. A. Oswe, "Human impact on lake ecosystems: The case of Lake Naivasha, Kenya," African Journal of Aquatic Science, vol. 32, no. 1, pp. 79-88, May 2007, doi: 10.2989/AJAS.2007.32.1.11.148.

42. B. M. Mati, S. Mutie, H. Gadain, P. Home, and F. Mtalo, "Impacts of land-use/cover changes on the hydrology of the transboundary Mara River, Kenya/Tanzania," Lakes and Reservoirs: Research and Management, vol. 13, no. 2, pp. 169-177, Jun. 2008, doi: 10.1111/j.1440-1770.2008.00367.x.

43. U. Kremser and E. Schnug, "Impact of fertilizers on aquatic ecosystems and protection of water bodies from mineral nutrients," Landbauforschung Volkenrode, vol. 52, no. 2, pp. 81-90, Jun. 2002.

44. T. M. Mutia, M. Z. Virani, W. N. Moturi, B. Muyela, W. J. Mavura, and J. O. Lalah, “Copper, lead and cadmium concentrations in surface water, sediment and fish, C. Carpio, samples from Lake Naivasha: Effect of recent anthropogenic activities," Environmental Earth Sciences, vol. 67, no. 4, pp. 1121-1130, Oct. 2012, doi: 10.1007/s12665-012-1556-8.

45. G. M. Ogendi, G. M. Maina, J. W. Mbuthia, H. K. Koech, C. M. Ratemo, and J. C. Koskey, "Heavy Metal Concentrations in Water, Sediments and Common Carp ( Cyprinus carpio) Fish Species from Lake Naivasha, Kenya," Research Journal of Environmental and Earth Sciences, vol. 6, no. 8, pp. 416-423, Aug. 2014, doi: 10.19026/rjees.6.5252.

46. H. Mwanake, "Application of the MONERIS model in the Lake Naivasha Catchment, Kenya," 2013. [Online]. Available: https://boku.ac.at/en/wau/ihg/arbeitsgruppen/ipgl-international-training-programmes-in-limnology/ipgl-master-theses

47. N. Kitaka, D. M. Harper, K. M. Mavuti, and N. Pacini, "Chemical characteristics, with particular reference to phosphorus, of the rivers draining into Lake Naivasha, Kenya," Hydrobiologia, vol. 488, pp. 57-71, Nov. 2002, doi: 10.1023/A:1023353825462.

48. M. Everard, J. A. Vale, D. M. Harper, and H. Tarras-Wahlberg, "The physical attributes of the Lake Naivasha catchment rivers," in Lake Naivasha, Kenya, Springer Netherlands, 2002, pp. 13-25. doi: 10.1007/978-94-017-2031-1_2.

49. N. Kitaka, D. M. Harper, and K. M. Mavuti, "Phosphorus inputs to Lake Naivasha, Kenya, from its catchment and the trophic state of the lake," in Lake Naivasha, Kenya, Springer Netherlands, 2002, pp. 73-80. doi: 10.1007/978-94-017-2031-1_6.

50. J. Ndungu, D. C. M. Augustijn, S. J. M. H. Hulscher, N. Kitaka, and J. Mathooko, "Spatio-temporal variations in the trophic status of Lake Naivasha, Kenya," Lakes and Reservoirs: Research and Management, vol. 18, no. 4, pp. 317-328, Dec. 2013, doi: 10.1111/Ire.12043.

51. S. C. Maberly, J. A. Pitt, P. S. Davies, and L. Carvalho, "Nitrogen and phosphorus limitation and the management of small productive lakes," Inland Waters, vol. 10, no. 2, 2020, doi: 10.1080/20442041.2020.1714384.

52. R. Shinohara et al., "Evaluation of the impact of water dilution within the hypereutrophic Lake Barato, Japan," Lake and Reservoir Management, vol. 24, no. 4, pp. 301-312, Dec. 2008, doi: 10.1080/07438140809354840.

53. R. A. Vollenweider and J. Kerekes, "THE LOADING CONCEPT AS BASIS FOR CONTROLLING EUTROPHICATION PHILOSOPHY AND PRELIMINARY RESULTS OF THE OECD PROGRAMME ON EUTROPHICATION," in Eutrophication of Deep Lakes, Elsevier, 1980, pp. 5-38. doi: 10.1016/b978-0-08-0260242.50005-5.

54. J. Onyango, N. Kreuzinger, and K. Nzula, Pesticides Residues Contamination in Lake Naivasha catchment, Kenya. AV Akademikerverlag, 2015. [Online]. Available: https://www.amazon.com/Pesticides-Residues-Contamination-Naivasha-catchment/dp/3639806093

55. S. Musa, J. W. Gichuki, P. O. Raburu, and C. M. Aura, "Organochlorine and organophosphorus pesticide residues in water and sediment from Yala/Nzoia River within Lake Victoria Basin, Kenya," Journal of Ecology and the Natural Environment, vol. 3, no. 12, pp. 392-399, 2011, [Online]. Available: http://www.academicjournals.org/JENE

56. J. Onyango, N. Kreuzinger, P. T. Yillia, and N. Kitaka, "Potential Risks of Pesticide Application in Kenya: Case of Lake Naivasha Catchment," 2014. [Online]. Available: https://www.academia.edu/18836365/Potential_Risks_of_Pesticide_Application_in_Kenya_Case_of_Lake_Naivasha_Catchment

57. P. M. Njogu, "Assessment of Pollution and Prediction of Environmental Risks of Organochlorine Pesticide Residues on Aquatic Communities in Lake Naivasha, Kenya," 2011.

58. J. Outa, N. Kitaka, and J. Kipkemboi, "Seasonal changes in water quality and biomass of water hyacinth in lake naivasha, Kenya," International Journal of Current Research, vol. 6, no. 11, pp. 9915-9925, 2014.

59. S. M. Gitahi, D. M. Harper, S. M. Muchiri, M. P. Tole, and R. N. Ng'ang'a, "Organochlorine and organophosphorus pesticide concentrations in water, sediment, and selected organisms in Lake Naivasha (Kenya)," in Lake Naivasha, Kenya, Springer Netherlands, 2002, pp. 123-128. doi: 10.1007/978-94017-2031-1_12.

60. J. Pretty et al., "Global assessment of agricultural system redesign for sustainable intensification," Nature Sustainability, vol. 1, no. 8, pp. 441-446, Aug. 2018, doi: 10.1038/s41893-018-0114-0. 
61. Z. T. Bainbridge, J. E. Brodie, J. W. Faithful, D. A. Sydes, and S. E. Lewis, "Identifying the land-based sources of suspended sediments, nutrients and pesticides discharged to the Great Barrier Reef from the Tully - Murray Basin, Queensland, Australia," Marine and Freshwater Research, 2009, doi: 10.1071/MF08333.

62. EU, Opinion on the Toxicity and Assessment of Chemical Mixtures. 2011. doi: 10.2772/37863.

63. C. A. Damalas and I. G. Eleftherohorinos, "Pesticide exposure, safety issues, and risk assessment indicators," International Journal of Environmental Research and Public Health. 2011. doi: 10.3390/ijerph8051402.

64. P. Durand et al., "Nitrogen processes in aquatic ecosystems," in The European Nitrogen Assessment, 2011. doi: 10.1017/cbo9780511976988.010.

65. G. Czub and M. S. McLachlan, "A food chain model to predict the levels of lipophilic organic contaminants in humans," Environmental Toxicology and Chemistry, vol. 23, no. 10, pp. 2356-2366, Oct. 2004, doi: 10.1897/03-317.

66. K. J. Rattan and P. A. Chambers, "Total, Dissolved and Particulate N:P Stoichiometry in Canadian Prairie Streams in Relation to Land Cover and Hydrologic Variability," Proceedings, 2017, doi: 10.3390/ecws-2-04952.

67. L. Cui and Z. Li, "The relationship between TN:TP ratio and phytoplankton nutrient limitation in Yanghe Reservoir," 2011. doi: 10.1109/ISWREP.2011.5893240.

68. D. R. Smith, H. P. Jarvie, and M. J. Bowes, "Carbon, Nitrogen, and Phosphorus Stoichiometry and Eutrophication in River Thames Tributaries, UK," Agricultural \& Environmental Letters, vol. 2, no. 1, p. ael2017.06.0020, Jan. 2017, doi: 10.2134/ael2017.06.0020.

69. F. Zabel, R. Delzeit, J. M. Schneider, R. Seppelt, W. Mauser, and T. Václavík, “Global impacts of future cropland expansion and intensification on agricultural markets and biodiversity," Nature Communications, vol. 10, no. 1, p. 2844, 2019, doi: 10.1038/s41467-019-10775-z.

70. L. Kehoe, A. Romero-Muñoz, E. Polaina, L. Estes, H. Kreft, and T. Kuemmerle, "Biodiversity at risk under future cropland expansion and intensification," Nature Ecology \& Evolution, vol. 1, no. 8, pp. 1129-1135, 2017, doi: 10.1038/s41559-017-0234-3.

71. R. Finger, S. M. Swinton, N. el Benni, and A. Walter, "Precision Farming at the Nexus of Agricultural Production and the Environment," Annual Review of Resource Economics, vol. 11, no. 1, pp. 313-335, Oct. 2019, doi: 10.1146/annurev-resource-100518-093929.

72. A. S. Davis, J. D. Hill, C. A. Chase, A. M. Johanns, and M. Liebman, "Increasing Cropping System Diversity Balances Productivity, Profitability and Environmental Health," PLOS ONE, 2012, doi: 10.1371/journal.pone.0047149.

73. A. Svanbäck et al., "Reducing agricultural nutrient surpluses in a large catchment - Links to livestock density," Science of The Total Environment, vol. 648, pp. 1549-1559, 2019, doi: https://doi.org/10.1016/j.scitotenv.2018.08.194.

74. I. H. Mohamad Ibrahim, L. Gilfoyle, R. Reynolds, and N. Voulvoulis, "Integrated catchment management for reducing pesticide levels in water: Engaging with stakeholders in East Anglia to tackle metaldehyde," Science of The Total Environment, vol. 656, pp. 1436-1447, 2019, doi:

https://doi.org/10.1016/j.scitotenv.2018.11.260.

75. D. Costa, H. Baulch, J. Elliott, J. Pomeroy, and H. Wheater, "Modelling nutrient dynamics in cold agricultural catchments: A review," Environmental Modelling \& Software, vol. 124, p. 104586, 2020, doi: https://doi.org/10.1016/j.envsoft.2019.104586.

76. UN Economic Commission for Africa, "The Africa Water Vision for 2025: Equitable and Sustainable Use of Water for Socioeconomic Development," Addis Ababa, 2000. [Online]. Available: https://www.ircwash.org/resources/africa-water-vision-2025-equitable-and-sustainable-use-water-socioeconomicdevelopment

77. Government of Kenya, Environmental Management and Coordination (Water Quality) Regulations, 2006 (Cap. 387). Kenya: Republic of Kenya, 2015, p. 25. [Online]. Available: http://extwprlegs1.fao.org/docs/pdf/ken84962.pdf

78. United Nations Water, "Implementing improvements in water quality and protecting ecosystem services," Geneva, Switzerland, 2015. [Online]. Available: https://www.un.org/waterforlifedecade/waterandsustainabledevelopment2015/images/water_quality_eng.pdf

79. E. Kumpel, R. Peletz, M. Bonham, and R. Khush, “Assessing Drinking Water Quality and Water Safety Management in Sub-Saharan Africa Using Regulated Monitoring Data," Environmental Science \& Technology, vol. 50, no. 20, pp. 10869-10876, Oct. 2016, doi: 10.1021/acs.est.6b02707.

80. Imarisha, "Imarisha's grand vision for the Lake Naivasha Basin," 2015. https://imarishanaivasha.wordpress.com/2015/01/12/imarishas-grand-vision-forthe-lake-naivasha-basin/ (accessed Aug. 31, 2020).

81. FAO, Legislative Approaches to Sustainable Agriculture and Natural Resources Governance. Rome, Italy: Food and Agriculture Organization of the United Nations (FAO), 2020. [Online]. Available: https://wedocs.unep.org/bitstream/handle/20.500.11822/32567/LASANRG.pdf?sequence=1\&isAllowed=y

82. United Nations Environment Programme, "Progress on ambient water quality. Tracking SDG 6 series: global indicator 6.3 .2 updates and acceleration needs.," Nairobi, 2021.

\section{Figures}




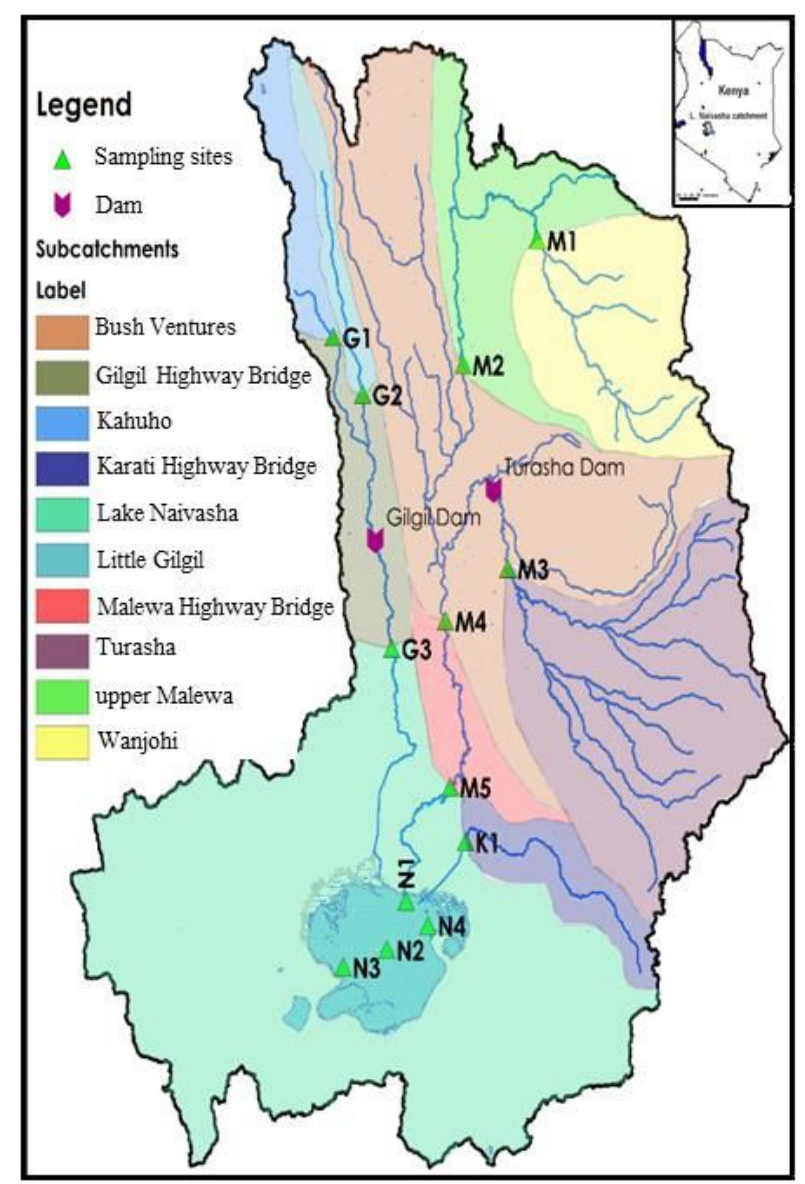

Figure 1

Lake Naivasha catchment and subcatchments, Kenya. Sampling sites are: G1= Kahuho, G2= Little Gilgil, G3 = Gilgil Highway Bridge, M1= Wanjohi, M2 = upper Malewa, M3 =Turasha, M4 = Bush Ventures, M5 = Malewa Highway Bridge, K1= Karati Highway Bridge, N1= River Mouth, N2 = Mid-lake, N3 = Hippo Point, N4 = Crescent. 


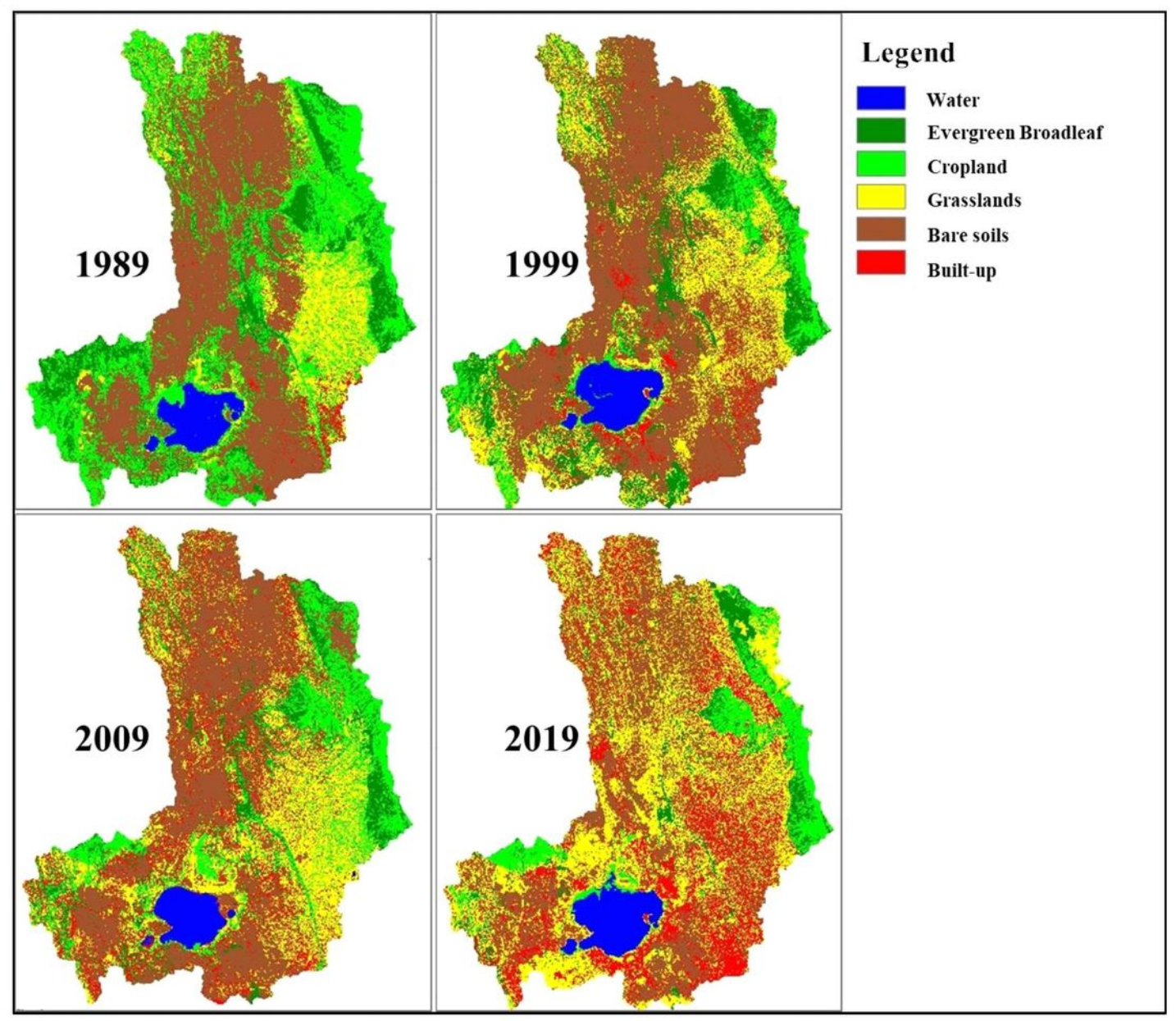

Figure 2

Decadal landuse changes from 1989 to 2019 


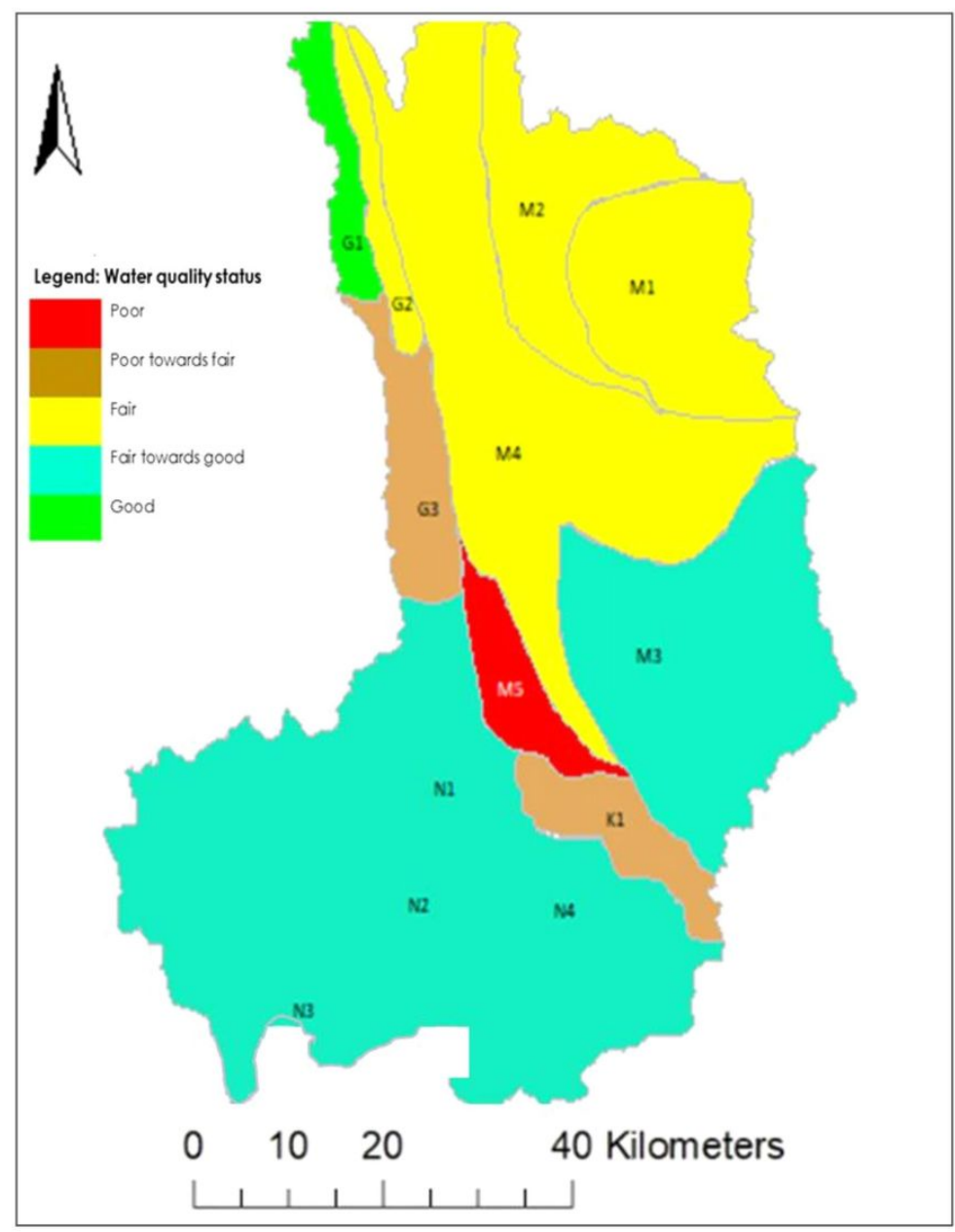

\section{Figure 3}

Water quality risk map for the sub-catchments of the Lake Naivasha catchment, Kenya.

\section{Supplementary Files}

This is a list of supplementary files associated with this preprint. Click to download.

- Highlights.docx

- SupplementaryTable1.docx

- Supplementarytable2.docx

- Supplementarytable3.docx

- SupplementaryTable4.docx

- SupplementaryTable5.docx

- SupplementaryTable6.docx 